\title{
Effect of $0.2 \%$ peracetic acid disinfection on the horizontal dimension of implant framework indexed with two autopolymerized acrylic resins
}

Emanuely Ronconi da Fonseca ${ }^{1}$, Paula Pereira Santana ${ }^{1}$, Anuar Antonio Xible², Donald A. Curtis ${ }^{3}$ and Stefania Carvalho Kano ${ }^{2^{*}}$ (D)

\begin{abstract}
Background: To minimize misfit between prosthesis and implant, the welding of the implant fixed partial denture (IFPD) framework is recommended and autopolymerized acrylic resin (AR) is the material of choice for the indexing process. As for any prosthetic device that comes into contact with saliva and blood in the oral cavity, IFPD indexed with AR must be disinfected before sending to the laboratory. However, disinfection procedures are often neglected for fear of shrinkage or distortion caused by a dimensional change of the acrylic resin. Peracetic acid is a high-level disinfectant agent at low concentrations and immersion time, with no reported toxic residues, and it is not inactivated in the presence of organic matter when compared to other disinfectants. This study aimed to evaluate the influence of $0.2 \%$ peracetic acid disinfectant solution after different storage media and times on the horizontal dimension of IFPD frameworks indexed with AR.
\end{abstract}

Material and methods: IFPD frameworks were indexed with two AR: group 1 Duralay and group 2 Pattern Resin LS. Each group was further divided into five subgroups according to disinfection procedure and storage medium: no disinfection and dry storage, no disinfection and water storage, $0.2 \%$ peracetic acid disinfection and water storage, $0.2 \%$ peracetic acid disinfection and peracetic acid storage, and $0.2 \%$ peracetic acid disinfection and dry storage. The horizontal dimension of the specimens and an average was established for analysis. Measurements were performed at four different storage times (hours): T0, T24, T48, T168.

Results: No statistical differences were found when T0 was compared to T168 for Pattern resin groups submitted to disinfection and storage in water (group $2 \mathrm{~b}, p=1.000$ ) or peracetic acid solution (group $2 \mathrm{c}, p=0.352$ ). For Duralay groups, the use of peracetic acid solution did not affect the horizontal dimension of the specimens when T0 was compared to T168 only with water as a storage medium (group 1b, $p=1.000$ ). Additionally, T0 did not differ from T24 for groups 1c $(p=0.553), 2 b(p=1.000), 2 d(p=0.234)$, and $2 e(p=1.000)$ and from T48 for groups $1 d$ $(p=0.118)$ and $2 \mathrm{~b}(p=1.000)$.

Conclusion: Within the studied conditions, the use of $0.2 \%$ peracetic acid can be safely used as a disinfectant solution regarding dimensional stability of AR-indexed IFPD until 7 days of storage. Horizontal discrepancies are dependent on acrylic resin type, time, and medium of storage.

Keywords: Dental implants, Disinfection, Prosthesis fitting, Peracetic acid

\footnotetext{
* Correspondence: stefaniakano@gmail.com

${ }^{2}$ Department of Prosthodontic, Universidade Federal do Espírito Santo, Av.

Marechal Campos, 1468 - Maruípe, Vitória, ES 29040-090, Brazil

Full list of author information is available at the end of the article
} 


\section{Background}

The long-term outcome of treatment with an implant may be compromised by the lack of adaptation between prosthesis and implant and can result in prosthesis failure, buildup of bacteria in soft and hard tissue, reactions as mucositis and periimplantites, and even loss of osseointegration [1-4]. As the several steps involving the fabrication of the prostheses can cause distortion, the welding of the implant fixed partial denture framework (IFPD) is recommended to minimize misfit between prosthesis and implant [5-7]. According to Branemark [8], misfits at the prosthesis level of up to $10 \mu \mathrm{m}$ can be biomechanically accepted and is considered a passive fit prosthesis. Although vertical discrepancies are commonly used for implant misfit analysis, horizontal misfits can also be harmful and should be used to evaluate framework fabrication techniques, since linear distortion can be created by contraction during the fabrication process of the prostheses [9]. When conventional welding is to be used, autopolymerized acrylic resin (AR) is the material of choice for the indexing process as described by Patterson [10], and the behavior of the material used to index the parts to be welded should be known [11].

As for any prosthetic device that contacts saliva and blood in the oral cavity, the IFPD joined with AR may become a vehicle for cross-contamination [12], therefore it should be cleaned and disinfected before being sent to the laboratory. Heat-sensitive critical and semi-critical instruments and devices can be sterilized by immersion in liquid chemical germicides having at least an intermediate level of activity [13].

Among the disinfectant solutions available, 2\% glutaraldehyde and $1 \%$ sodium hypochlorite have been widely used, and both are linked with a variety of health effects and require longer immersion time when compared to peracetic acid. Additionally, both are inactivated by organic matter [13-16].

Peracetic acid is a liquid chemical germicide listed as a sterilant and high-level disinfection product that has been used for medical and dental purposes [16-20]. The increased interest on peracetic acid is due to its effective broad-spectrum disinfection properties with bactericidal, virucidal, and sporicidal effect and no reported toxic residues [17]. Peracetic acid acts rapidly against all microorganisms even at low concentrations and low immersion time and is not inactivated in the presence of organic matter when compared to other disinfectants such as sodium hypochlorite and glutaraldehyde $[13,17]$. There is also a concern about the effect of these disinfectants on acrylic resin properties [17].

Autopolymerized acrylic resin presents polymerization shrinkage, which it may be influenced by storage time and medium [21-25], suggesting that indexed prostheses should be sent as soon as possible for laboratory processing to minimize distortion. Usually, the period from clinical indexing procedure and laboratory processing takes 24 or more hours to be performed and can take longer if dental clinics and laboratory are not located in the same area.

The main objective of this work was to evaluate the horizontal dimensional stability of IFPcection with $0.2 \%$ peracetic acid solution and after different media and times of storage.

\section{Material and methods Specimen fabrication}

On a master template with two external hexagon-type implants of $3.75 \mathrm{~mm}$ and $4.1 \mathrm{~mm}$ platform (Neodent, Curitiba, Paraná, Brazil), metal IFPD infrastructures were fabricated using hexagonal UCLA casting cylinders (Neodent, Curitiba, Paraná, Brazil) attached by $2.5 \mathrm{~mm}$ in diameter cylindrical prefabricated wax bar (Ceras Babinete Ltda, Maringá, Paraná, Brazil) positioned $4 \mathrm{~mm}$ above the base (Fig. 1).

Waxed specimens were included and cast with $\mathrm{CoCr}$ alloy (CoCr DeguDent, Dentsply, São Paulo, Brazil) by centrifugal technique, following the manufacturer's recommendations. After casting, specimens were sandblasted and internal surfaces were inspected with a $3.5 \times$ magnifier (Bio-Art, São Carlos, São Paulo, Brazil). Each specimen was then sectioned with an aluminum oxide disc (Dentorium International Incorporated, New York, USA) with an approximate thickness of $0.3 \mathrm{~mm}$.

\section{Indexing process}

Specimens were manually screwed in place and $32 \mathrm{Ncm}$ torque was applied to the screws with a torque wrench (Ratchet Wrench, Neodent, Curitiba, Brazil), indexed with $\mathrm{AR}$, and allowed to cure for $10 \mathrm{~min}$. During the indexing procedure, autopolymerized acrylic resin was

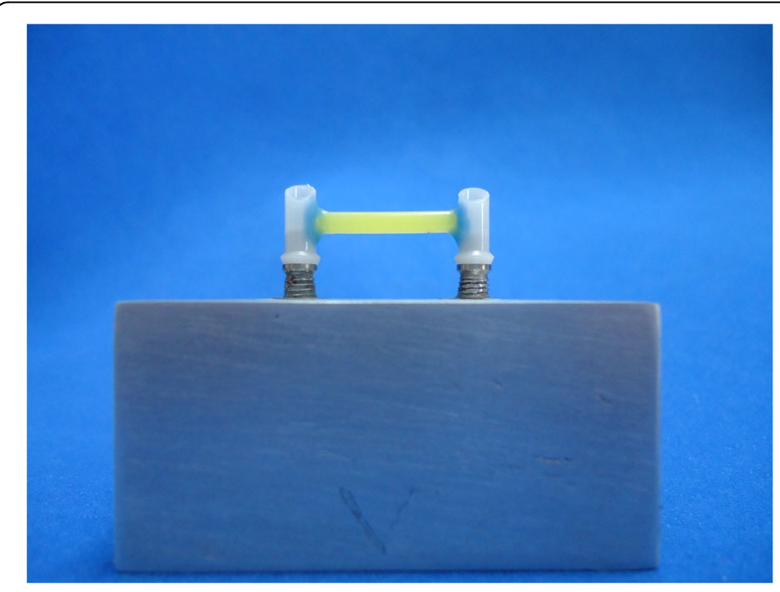

Fig. 1 UCLA casting cylinders attached with wax bar before casting 
inserted with the aid of a brush using the technique described by Nealon [26] and a silicon model to standardize AR volume (Fig. 2).

\section{Measurement of the horizontal dimension of the specimen}

All IFPD frameworks were unscrewed from the master model (Fig. 2c) and were taken to the video optical measuring instrument for image processing (Tesa Visio 200 model, Renes, Switzerland) with an accuracy of $1 \mu \mathrm{m}$, to measure horizontal dimension alteration. The horizontal dimension was the total length between the abutments at the most distal prosthetic surface of the IFPD on the $x$-axis of the machine and was completed with transmitted light illumination (Fig. 3).

The first measurement was performed $10 \mathrm{~min}$ after polymerization of AR (T0). To evaluate the effect of storage time and storage medium on the horizontal dimension of the AR, additional measurements were taken at three different moments (Table 1): T24, 24h of storage; T48, $48 \mathrm{~h}$ of storage; and T168, $168 \mathrm{~h}$ or 7 days of storage.

Each specimen at each moment of analysis was measured three times, and a mean horizontal dimension (millimeters) of each specimen was obtained. All measurements were completed by a single clinician who was blinded to both the disinfection/storage procedure and type of AR.

During the whole experimental period, specimens were stored in controlled room temperature $\left(20 \pm 2{ }^{\circ} \mathrm{C}\right)$ and $50 \%$ relative air humidity.

\section{Disinfection/storage procedures and specimen grouping}

The specimens were aleatorily divided into two groups according to the AR used: group 1 Duralay (Reliance Dental Mfg. Co., IL, USA) and group 2 Pattern Resin LS (GC AMERICA Inc., IL, USA). Further, each group was divided into five subgroups with 16 specimens each $(n=16)$ according to disinfection/storage condition (Table 2).

Groups 1a and 2a were not submitted to the disinfection procedure and were stored in water. Groups 1e and 2e were not submitted to the disinfection procedure and were stored in dry condition. Groups 1b, 2b, 1c, 2c, 1d, and $2 \mathrm{~d}$ were submitted to the same disinfection protocol but different storage conditions after disinfection. Groups $1 \mathrm{~b}$ and $2 \mathrm{~b}$ were stored in water, groups $1 \mathrm{c}$ and $2 \mathrm{c}$ were stored in $0.2 \%$ peracetic acid, and groups $1 \mathrm{~d}$ and $2 \mathrm{~d}$ were stored in dry condition.

The disinfection protocol used was a high-level disinfection according to the manufacturer's recommendation and consisted of a 10 min immersion in $0.2 \%$ peracetic acid (PERAX RIO, Rioquímica, São José do Rio Preto, São Paulo, Brazil), followed by rinsing in physiological solution of $0.9 \%$ sodium chloride (Arboreto, Juiz de Fora, Minas Gerais, Brazil).

Groups 1a, 2a, 1e, and 2e were not submitted to a disinfection procedure and were used as a control group to compare the horizontal dimensional change when specimens are submitted to disinfection procedure with $0.2 \%$ peracetic acid (groups 1b, 2b, 1c, 2c, 1d, and 2d).

Data were treated with the statistical program SPSS 24 (IBM, Armonk, NY, USA) with repeated measures ANOVA and differences established with a Bonferroni test. The significance level adopted was 5\%.

\section{Results}

The results for the horizontal dimension (mean and standard deviation) for all groups according to the time of storage are presented in Table 3. Post hoc Bonferroni test was used to detect differences between groups.

The use of $0.2 \%$ peracetic acid as disinfectant did not affect the horizontal dimension of Pattern resin groups when T0 was compared to T168 if specimens were not stored in dry medium (group 2b, $p=1.000$; group 2c, $p=0.352$ ). The same was true for Duralay resin groups only when stored in water (group $1 \mathrm{~b}, p=1.000$ ). The use of $0.2 \%$ peracetic acid as disinfectant followed by water storage did not alter the horizontal dimension of Pattern resin (group 2b) when T0 was compared to all storage times (T24, T48, T168) $(p=1.000)$.

After disinfection, horizontal contraction was observed after $24 \mathrm{~h}$ (T24) for groups 2c, 1b, and 1d and after $48 \mathrm{~h}$ (T48) for groups $2 \mathrm{c}, 2 \mathrm{~d}, 1 \mathrm{~b}$, and $1 \mathrm{c}(p \leq 0.05)$. When comparing storage medium (dry $\times$ water) and no disinfection, Duralay resin groups (1a and 1e) presented a
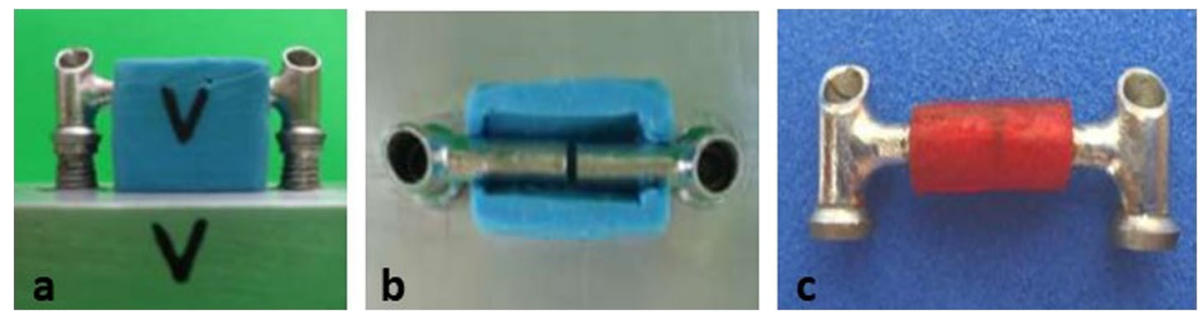

Fig. $\mathbf{2}$ a, b Silicon model to standardize resin volume. c IFPD indexed with acrylic resin 


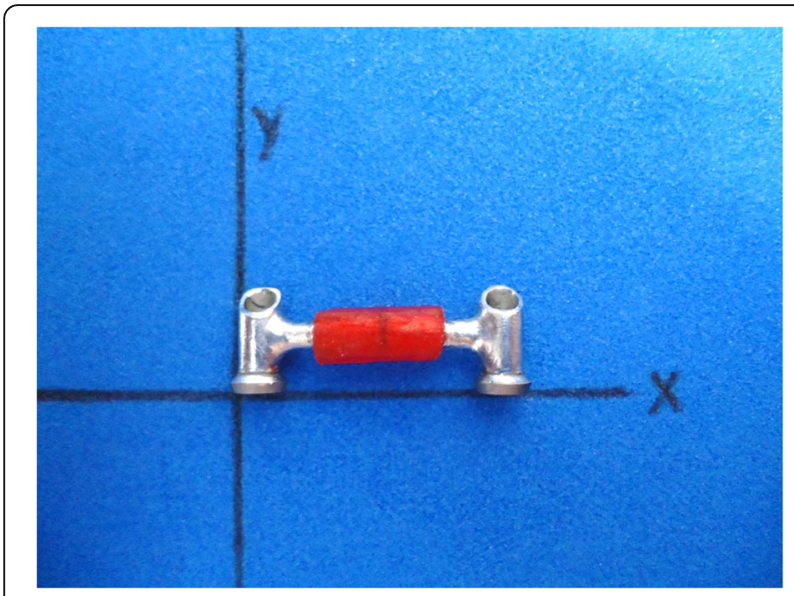

Fig. 3 Horizontal dimension considering the length between the most distal prosthetic surfaces of the framework

statistically significant reduction of the horizontal dimension when T0 was compared to all storage times (T24, T48, and T168). For Pattern resin groups (2a and $2 \mathrm{e})$, when T0 was compared to T168, no differences were found for group $2 \mathrm{a}(p=0.053)$ and $2 \mathrm{e}(p=0.208)$ and also when T0 was compared to T24 for group $2 \mathrm{e}$ $(p=1.000)$. Figure 4 shows the variance of horizontal dimension for all groups analyzed.

\section{Discussion}

The guidance of the American Dental Association and the Center for Disease Control and Prevention recommend that all denture devices must be disinfected before they are sent to the laboratory technician to eliminate cross-contamination [27]. In this study, we used $0.2 \%$ peracetic acid for disinfection of the specimens and as storage medium after indexing the IFPDs with acrylic resin, to assess whether peracetic acid as a disinfection product and as a storage medium would cause horizontal dimensional changes on the acrylic resin used to index IFPDs for soldering.

The use of peracetic acid on microbiological disinfection was reported previously [28] and successfully managed the disinfection of the samples after $5 \mathrm{~min}$ and 10 min of immersion [17, 28]. In our study, the disinfection protocol with $0.2 \%$ peracetic acid consisted of $10 \mathrm{~min}$ immersion, according to the manufacturer's recommendation for high-level disinfection. Results of this study

Table 1 Description of storage time

\begin{tabular}{ll}
\hline Storage time & Description \\
\hline T0 & Initial measurement \\
T24 & $24 \mathrm{~h}$ of storage \\
T48 & $48 \mathrm{~h}$ of storage \\
T168 & $168 \mathrm{~h}$ or 7 days of storage \\
\hline
\end{tabular}

Table 2 Group description according to disinfection procedure and storage medium $(n=160)$

\begin{tabular}{lll}
\hline Description & $\begin{array}{l}\text { Group 1 (Duralay) } \\
(n=80)\end{array}$ & $\begin{array}{l}\text { Group 2 (Pattern) } \\
(n=80)\end{array}$ \\
\hline No disinfection, water storage & $1 \mathrm{a}$ & $2 \mathrm{a}$ \\
$\begin{array}{l}\text { Disinfection in 0.2\% } \\
\text { peracetic acid for 10 } \\
\text { min and water storage }\end{array}$ & $1 \mathrm{~b}$ & $2 \mathrm{~b}$ \\
$\begin{array}{l}\text { Disinfection in 0.2\% } \\
\text { peracetic acid for 10 min } \\
\text { and peracetic acid storage }\end{array}$ & $1 \mathrm{c}$ & $2 \mathrm{c}$ \\
$\begin{array}{l}\text { Disinfection in 0.2\% } \\
\text { peracetic acid for 10 min } \\
\text { and dry storage }\end{array}$ & $1 \mathrm{~d}$ \\
$\begin{array}{l}\text { No disinfection, } \\
\text { dry storage }\end{array}$ & $1 \mathrm{e}$ & $2 \mathrm{~d}$ \\
\hline
\end{tabular}

showed that the use of $0.2 \%$ peracetic acid for disinfection with water storage (group $2 \mathrm{~b}$ ) or disinfection and as a storage medium (group 2c) produced no significant horizontal dimensional alteration after 7 days (T168) for Pattern resin groups. For Duralay resin, the use of $0.2 \%$ peracetic acid produced a positive significant horizontal dimension alteration when compared to groups 1a and 1e where no disinfection was performed and contraction was observed in all times of storage. Peracetic acid was useful in compensating the shrinkage of the resin for groups 1b (T168), 1c (T24), and 1d (T48).

Superficial changes of the acrylic resins have been evaluated by Chassot et al. [17] who demonstrated that peracetic acid did not affect superficial roughness and color of the resins. However, limited literature is available about the effect of the peracetic acid solution on metallic surfaces $[18,28]$ and further studies are needed. Additionally, some authors have reported adverse effects of exposure to peracetic acid in higher concentrations (2\%) by hospital cleaning staff, such as work-shift eye and upper and lower airway symptoms [29], but no report is available for low concentration as $0.2 \%$ peracetic acid solution in dental use.

McDonnell et al. [21] evaluated the accuracy of Pattern and Duralay resin as indexing material after $15 \mathrm{~min}$, $2 \mathrm{~h}$, and $24 \mathrm{~h}$, using the Sheffield 1 -screw test as an outcome measure. They found that both acrylic resins were assessed accurately for fit $15 \mathrm{~min}$ after polymerization only. The authors recommended that implant assemblies should be invested as soon as possible. Also, according to McDonnell et al. and Dumbrigue et al. [21, 30], AR suffers volumetric shrinkage in the first $24 \mathrm{~h}$. The conclusion of the authors was related only to the polymerization properties of the acrylic resin, considering storage in a dry medium. In our study, AR contraction was observed after $24 \mathrm{~h}$ of storage for most of the groups of Duralay resin groups (groups 1a, 1b, 1d, and 1e), 
Table 3 Mean values and standard deviation of the horizontal dimension of the specimens (millimeters) for all groups at all storage time $(n=160)$

\begin{tabular}{|c|c|c|c|c|c|}
\hline Group & Storage time & Mean & Standa & d deviation (SD) & $p$ \\
\hline \multirow[t]{4}{*}{$1 \mathrm{a}$} & T0 & $25,511.48^{c}$ & 70.09 & & \multirow[t]{4}{*}{$<0.001$} \\
\hline & T24 & $25,506.52^{\mathrm{ab}}$ & 71.44 & & \\
\hline & T48 & $25,504.1^{\mathrm{a}}$ & 70.61 & & \\
\hline & T168 & $25,507.4^{b}$ & 70.63 & & \\
\hline \multirow[t]{4}{*}{$1 b$} & TO & $25,525.54^{b}$ & 50.6 & & \multirow[t]{4}{*}{$<0.001$} \\
\hline & T24 & $25,518.87^{a}$ & 50.28 & & \\
\hline & $\mathrm{T} 48$ & $25,518.29^{a}$ & 50.36 & & \\
\hline & $\mathrm{T} 168$ & $25,524.9^{b}$ & 50.24 & & \\
\hline \multirow[t]{4}{*}{$1 c$} & TO & $25,536.9^{c}$ & 45.64 & & \multirow[t]{4}{*}{$<0.001$} \\
\hline & T24 & $25,534.88^{b c}$ & 42.95 & & \\
\hline & T48 & $25,530.58^{\mathrm{a}}$ & 43.58 & & \\
\hline & T168 & $25,531.6^{a b}$ & 45.28 & & \\
\hline \multirow[t]{4}{*}{$1 d$} & TO & $25,519.36^{b}$ & 40.44 & & \multirow[t]{4}{*}{$<0.001$} \\
\hline & T24 & $25,512.52^{a}$ & 40.33 & & \\
\hline & T48 & $25,515.35^{\mathrm{ab}}$ & 42.55 & & \\
\hline & T168 & $25,513.4^{\mathrm{a}}$ & 41.76 & & \\
\hline \multirow[t]{4}{*}{ le } & T0 & $25,532.69^{b}$ & 52.65 & & \multirow[t]{4}{*}{$<0.001$} \\
\hline & T24 & $25,523.33^{\mathrm{a}}$ & 57.56 & & \\
\hline & T48 & $25,525.69^{\mathrm{a}}$ & 55.83 & & \\
\hline & T168 & $25,524.25^{\mathrm{a}}$ & 56.11 & & \\
\hline \multirow[t]{4}{*}{$2 a$} & TO & $25,536.71^{b}$ & 46.65 & & \multirow[t]{4}{*}{$<0.001$} \\
\hline & T24 & $25,531.31^{a}$ & 46.4 & & \\
\hline & T48 & $25,532.81^{a}$ & 47.22 & & \\
\hline & T168 & $25,533.94^{\mathrm{ab}}$ & 45.72 & & \\
\hline \multirow[t]{4}{*}{$2 b$} & T0 & $25,541.44$ & 48.77 & & \multirow[t]{4}{*}{0.598} \\
\hline & T24 & $25,536.71$ & 49.02 & & \\
\hline & T48 & $25,537.29$ & 50.17 & & \\
\hline & $\mathrm{T} 168$ & $25,538.21$ & 52.27 & & \\
\hline \multirow[t]{4}{*}{$2 c$} & T0 & $25,483.96^{\mathrm{b}}$ & 85.47 & & \multirow[t]{4}{*}{0.001} \\
\hline & T24 & $25,479.67^{a}$ & 85.96 & & \\
\hline & T48 & $25,477.58^{\mathrm{a}}$ & 86.96 & & \\
\hline & T168 & $25,480.85^{\mathrm{ab}}$ & 87.27 & & \\
\hline \multirow[t]{4}{*}{$2 d$} & T0 & $25,557.98^{b}$ & 63.04 & & \multirow[t]{4}{*}{0.003} \\
\hline & T24 & $25,554.98^{\mathrm{ab}}$ & & 62.15 & \\
\hline & T48 & $25,552.85^{\mathrm{C}}$ & & 62.11 & \\
\hline & T168 & $25,555.21^{a c}$ & & 63.04 & \\
\hline \multirow[t]{4}{*}{$2 e$} & TO & $25,538.73^{b}$ & & 56.23 & \multirow[t]{4}{*}{0.005} \\
\hline & T24 & $25,536.98^{\mathrm{ab}}$ & & 55.96 & \\
\hline & T48 & $25,533.42^{a}$ & & 54.06 & \\
\hline & T168 & $25,535.23^{\mathrm{ab}}$ & & 53.69 & \\
\hline
\end{tabular}

Different letters (abc) indicate significant differences between means (Bonferroni multiple comparison test)

Significant level for Repeated measures ANOVA were in bold except for group 1c $(p=0.553)$, where disinfection and storage were performed with $0.2 \%$ peracetic acid. And for Pattern resin groups, contraction after $24 \mathrm{~h}$ (T24) was observed for groups 2a (no disinfection and storage in dry medium) and 2c (disinfection and storage in peracetic acid solution). According to our findings, laboratory processing of Pattern resin disinfected with $0.2 \%$ peracetic acid should be delayed for more than $48 \mathrm{~h}$ at least, to overcome AR shrinkage at $24 \mathrm{~h}$ and $48 \mathrm{~h}$, when also stored in $0.2 \%$ peracetic solution. If stored in dry medium, laboratory processing should be performed within $24 \mathrm{~h}$ (Fig. 4). If stored in water, right after $0.2 \%$ peracetic acid disinfection, laboratory processing can be done until 7 days without horizontal dimensional change of the AR.

On the other hand, results obtained by Pattern resin (groups 2b, 2c, and 2d) that were immediately immersed in a $0.2 \%$ peracetic solution for $10 \mathrm{~min}$ demonstrated a contraction after $24 \mathrm{~h}$ (group 2c) and $48 \mathrm{~h}$ (groups 2c and $2 \mathrm{~d}$ ), but after 7 days of storage (T168), the horizontal dimension of the specimens was the same as initial measures (T0) for groups $2 \mathrm{~b} \quad(p=1.000)$ and 2c $(p=0.352)$; therefore, laboratory processing should be delayed. For the Duralay resin group, laboratory processing should be delayed for 7 days for group $1 \mathrm{~b}, 24 \mathrm{~h}$ for group $1 \mathrm{c}$, and $48 \mathrm{~h}$ for group $1 \mathrm{~d}$, when horizontal dimension was the same as the initial dimension (T0).

When comparing the two types of acrylic resin (Pattern $\times$ Duralay), most of Pattern resin groups recovered its initial horizontal dimension after 7 days (T168) of storage, regardless of the type of storage (dry $\times$ water $\times$ peracetic acid) and the use of disinfection solution (no disinfection $\times$ disinfection), except for group $2 d$ (disinfection followed by dry storage medium). The Duralay resin group, however, presented no consistent results. Groups not submitted to disinfection (groups 1a and 1e) showed contraction in all storage times, and for those groups submitted to disinfection (groups 1b, 1c, and 1d), only the storage water (group $1 \mathrm{~b}$ ) recovered the horizontal dimension after 7 days.

A couple of limitations must be cited in this study: although one of the purposes of it was to simulate the real clinical steps of indexing IFPDs, it must be considered that a real IFPD would ideally present a larger soldering area, around $9 \mathrm{~mm}^{2}$, and therefore, it would need a larger amount of AR for the indexing process. Ultimately, results could evidence differently from the present study. A second limitation was that AR used for indexing IFPDs are subjected to dimensional changes that vary from contraction to expansion, but it is not clear how much of each contribute to the changes observed over the time and if any other factor may play a role in the process. Therefore, further studies should be directed to compare different amounts of resins. 


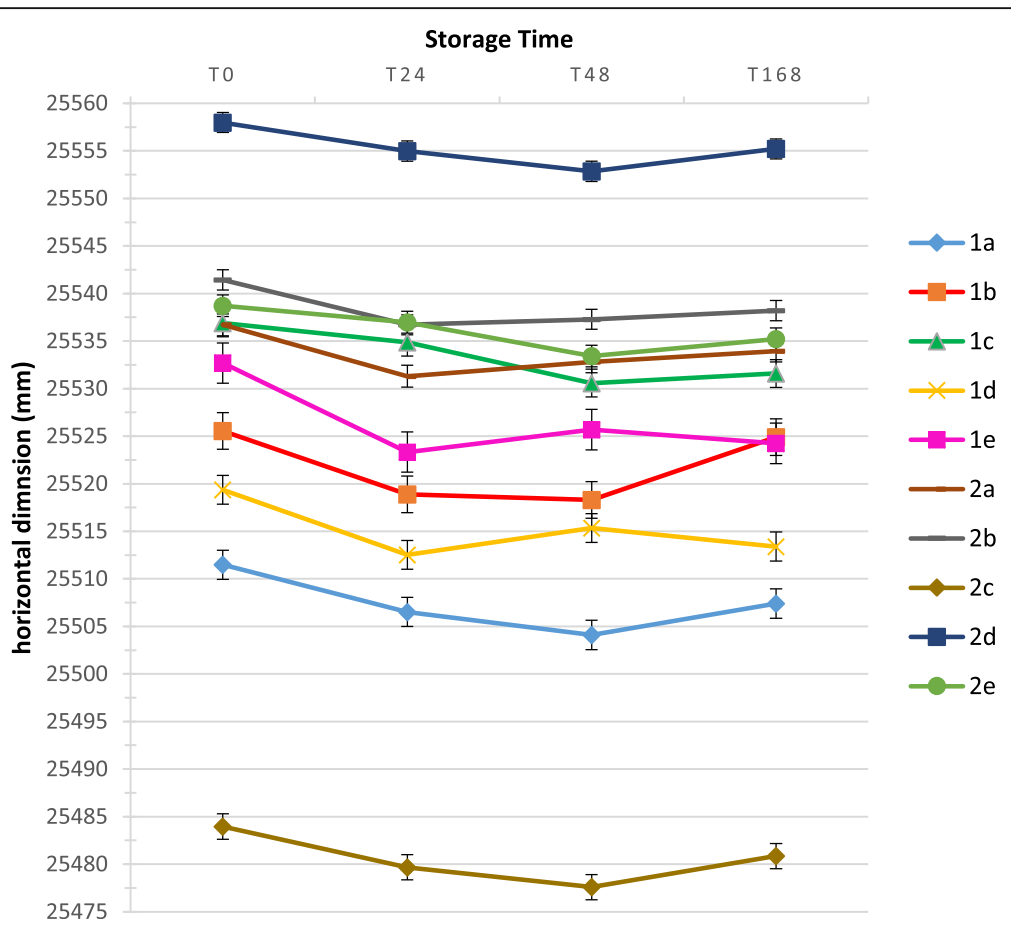

Fig. 4 Horizontal dimension for all groups analyzed at all storage times

\section{Conclusion}

Within the studied conditions, the use of $0.2 \%$ peracetic acid can be safely used as a disinfectant solution regarding the dimensional stability of AR-indexed IFPD until 7 days of storage. Horizontal discrepancies are dependent on acrylic resin type, time, and medium of storage.

\section{Abbreviations}

AR: Autopolymerized acrylic resin; CoCr: Cobalt-chrome; IFPD: Implant fixed partial denture; SD: Standard deviation

\section{Acknowledgements}

Not applicable

\section{Authors' contributions}

ERF and PPS prepared the specimens, performed the tests and measurements, wrote the paper, and helped in analyzing the results. SCK worked on the measurements. SCK and AAX analyzed and interpreted the data. DAC was a major contributor in writing the final paper and also responsible for the English review of the manuscript. All authors read and approved the final manuscript

\section{Funding}

This study was financed in part by the Coordenação de Aperfeiçoamento de Pessoal de Nível Superior - Brasil (CAPES) - Code 001 and Fundação de Amparo à Pesquisa e Inovação do Espírito Santo.

\section{Availability of data and materials}

The datasets used and/or analyzed during the current study are available from the corresponding author on reasonable request.

Ethics approval and consent to participate Not applicable

\section{Consent for publication}

Not applicable

\section{Competing interests}

Emanuely Ronconi da Fonseca, Paula Pereira Santana, Anuar Antonio Xible, Donald A Curtis, and Stefania Carvalho Kano declare that they have no competing interests.

\section{Author details}

${ }^{1}$ Clinical Dentistry Master Program, Universidade Federal do Espiríto Santo, Av. Marechal Campos, 1468 - Maruípe, Vitória, ES 29040-090, Brazil. ${ }^{2}$ Department of Prosthodontic, Universidade Federal do Espírito Santo, Av. Marechal Campos, 1468 - Maruípe, Vitória, ES 29040-090, Brazil. ${ }^{3}$ Department of Preventive and Restorative Dental Sciences, School of Dentistry, University of California, San Francisco, 707 Parnassus Avenue, San Francisco, CA 94143-0758, USA.

Received: 4 April 2019 Accepted: 23 August 2019

Published online: 18 September 2019

\section{References}

1. Kano SC, Bonfante G, Hussne R, Siqueira AF. Use of base metal casting alloys for implant framework: marginal accuracy analysis. J Appl Oral Sci. 2004:12(4):337-47.

2. Helldén $L B$, Dérand T. Description and evaluation of a simplified method to achieve passive fit between cast titanium frameworks and implants. Int J Oral Maxillofac Implants. 1998;13:190-6.

3. Jemt T, Book K. Prosthesis misfit and marginal bone loss in edentulous implant patients. Int J Oral Maxillofac Implants. 1996;11:620-5.

4. Taylor TD, Agar JR, Vogiatzi T. Implant prothodontics: current perspective and future directions. Int J Oral Maxillofac Implants. 2000;15:66-75.

5. Barbosa GA, Simamoto Junior PC, Fernandes Neto AJ, de Mattos MG, Neves FD. Prosthetic laboratory influence on the vertical misfit at the implant/ UCLA abutment interface. Braz Dent J. 2007;18:139-43.

6. Schiffleger BE, Ziebert GJ, Dhuru VB, Brantley WA, Sigaroudi K. Comparison of accuracy of multiunit one-piece castings. J Prosthet Dent. 1985;54:770-6. 
7. Waskewicz GA, Ostrowski JS, Parks VJ. Photoelastic analysis of stress distribution transmited from the fixed prosthesis attached to osseointegrated implants. Int J Oral Maxillofac Implants. 1994;9:405-11.

8. Branemark PI. Osseointegration and its experimental background. J Prosthet Dent. 1983;50:399-410.

9. Spazzin AO, Santos MBF, Sobrinho LC, Consani RLX, Mesquita MF. Effects of horizontal misfit and bar framework material on the stress distribution of an overdenture-retaining bar system: a 3D finite element analysis. J Prosthodont. 2011;20:517-22.

10. Patterson JC. A technique for accurate soldering. J Prosthet Dent. 1972;28: 552.

11. Byrne G. Soldering in prosthodontics-an overview, part I. J Prosthodont. 2011:20:233-43.

12. Tuna SH, Keyf F, Gumus HO, Uzun C. The evaluation of water sorption/ solubility on various acrylic resins. Eur J Dent. 2008:2:191-7.

13. Rutala WA, Weber DJ, and the Healthcare Infection Control Practices Advisory Committee (HICPAC). Guideline for disinfection and sterilization in healthcare facilities, 2008. Update: May 2019. https:/www.cdc.gov/ infectioncontrol/guidelines/disinfection. Accessed 15 July 2019.

14. Best Practices for the Safe Use of Glutaraldehyde in Health Care, OSHA document number 3258-08N-2006. https://www.osha.gov/Publications/325 8-08N-2006-English.html. Accessed 15 July 2019.

15. Jin-Hong Y. Review of disinfection and sterilization - back to the basics. Infect Chemother. 2018;50(2):101-9.

16. Hernandez A, Martro E, Matas L, Ausina V. In-vitro evaluation of Pearsafe compared with $2 \%$ alkaline glutaraldehyde against Mycobacterium spp. J Hosp Infect. 2003;54:52-6.

17. Chassot AL, Poisl ML, Samuel SM. In vivo and in vitro evaluation of the efficacy of peracetic acid-based the disinfectant for decontamination of acrylic resins. Braz Dent J. 2006;17:117-21.

18. Raimundo $L B$, et al. Effects of peracetic acid on the corrosion resistance of commercially pure titanium (grade 4). Braz Dent J. 2015;26(6):660-6.

19. Rohtash, Singh AK, Kumar R. Corrosion study of stainless steels in peracetic acid bleach media with and without chloride and chelant. Int I Res Innov Sci Technol. 2014;1:1): 1-10.

20. Loukili NH, Granbastien B, Faure K, Guery B, Beaucaire G. Effect of different stabilized preparation of peracetic acid on biofilm. J Hosp Infect. 2006;63(1):70-2

21. McDonnell T, Houston F, Byrne D, Gorman C, Claffey N. The effect of timelapse on the accuracy of two acrylic resins used to assemble an implant framework for soldering. J Prosthet Dent. 2004;91:538-40.

22. Mojon P, Oberholzer JP, Meyer JM, Belser UC. Polymerization shrinkage of index and pattern acrylic resins. J Prosthet Dent. 1990;64:684-8.

23. Sabouhi M, Nosoushian S, Dakhilalian M, Davoudi A, Mehrad R. The effect of time and storage environment on dimensional changes of acrylic resin post patterns. Open Dent J. 2015;9:87-90.

24. Cho GC, Chee WWL. Efficient soldering index materials for fixed partial dentures and implant substructures. J Prosthet Dent. 1995:73:424-7.

25. Rubenstein JE, Lowry MB. A comparison of two solder registration materials: three-dimensional analysis. J Prosthet Dent. 2006:95(5):379-91.

26. Nealon FH. Acrylic restorations by the operative nonpressure procedure. J Prosthet Dent. 1952;2:513-27.

27. Council on Dental Materials, Instrument, and Equipment, Council on Dental Practice, Council on Dental Therapeutics. Infection control recommendations for the dental office and the dental laboratory. J Am Dent Assoc. 1996;127:672-80

28. Costa SAS, Paula OFP, Silva CRG, Leão MVP. Stability of antimicrobial activity of peracetic acid solutions used in the final disinfection process. Braz Oral Res. 2015;29(1):1-6.

29. Hawley B, et al. Respiratory symptoms in hospital cleaning staff exposed to a product containing hydrogen peroxide, peracetic acid, and acetic acid. Ann Work Expo Health. 2017:62(1):28-40.

30. Dumbrique HB, Gurun DC, Javid NS. Prefabricated acrylic resin bars for splinting implant transfer copings. J Prosthet Dent. 2000;84:108-10.

\section{Publisher's Note}

Springer Nature remains neutral with regard to jurisdictional claims in published maps and institutional affiliations.

\section{Submit your manuscript to a SpringerOpen ${ }^{\circ}$ journal and benefit from:}

- Convenient online submission

- Rigorous peer review

- Open access: articles freely available online

- High visibility within the field

- Retaining the copyright to your article

Submit your next manuscript at $\boldsymbol{\triangleright}$ springeropen.com 